taria proseguir este camino y rastrear a fondo aquellas utopías optimistas que Cervantes combate.

Nos hemos detenido en resaltar aquellos aspectos en que la cultura española coincide con la del resto de Europa, tarea que Maravall viene persiguiendo. En definitiva, rompe lanzas (sin decirlo), contra aquellos que han sostenido la discontinuidad de la cultura peninsular (el Ortega de la España invertebrada) y la realidad histórica de España, de Castro, cuya hipótesis es que parte de Europa geográficamente se fue "alejando cada vez más de ella". "Falacia es - dice Castro- sostener que España siempre estuvo enlazada con Europa, $y$ siguió en su vida un curso paralelo al de los otros pueblos de Occidente" (intr., ed. 1965). Maravall corrobora lo contrario. Sus estudios abundan en observaciones pertinentes y enriquecedoras para la historia de las ideas y la historia cultural. Por mi parte, no se me ocurre ninguna objeción fundamental, como máximo los añadidos que he apuntado en torno al siglo xvir.

Señalemos, para terminar, que Maravall ha compilado en fecha reciente sus monografías sobre aspectos intelectuales específicos de los siglos xvi y xvn, trabajos que permiten aclarar los estudios sucesivos de su pensamiento y su itinerario intelectual ${ }^{18}$. La riqueza de sus planteamientos, como hemos visto, se centra en la relación entre España y Europa. Sin duda, sus libros volverán a impulsar la investigación sobre temas fundamentales. Sobre todo, la estrecha relación entre los postrimeros años del siglo hechizado y los albores de las luces.

IRIS M. ZAVALA

State University of New York at Stony Brook.

\title{
LA ESTÉTICA EXTRAVASANTE DE LA INNEGAUSENCIA O LA MODERNIDAD DE ARQUELES VELA
}

"El género novela -según Ángel Rama- es el pez enjabonado de la literatura"1. Pero, si atraparlo como género es difícil, igualmente esquiva resulta la fijación genésica de sus variantes en una escala evolutiva, pues "de sus bajos fondos originarios [la novela] extrajo su capacidad de adaptación, de supervivencia, de transformación"'. De ahí, en la historiografía tradicional de la novela americana no sólo las lagunas sino las confusiones en cuanto a las normas de su desarrollo, sobre todo, respecto

18 Una sucinta síntesis de sus ideas del barroco se encuentran en "Un esquema conceptual de la cultura barroca", $\mathrm{CuH}, 273$ (1973). La mayor parte de sus articulos se encuentran en Estudios de Historia y pensamiento español (Serie Primera, Edad Media), Madrid, 1973; Estudios de historia del pensamiento español. Siglo xvii, Madrid, 1975. Últimamente se centra en el xvir; fuera de ello vale consultar su espléndido artículo "Relaciones de dependencia e integración social: criados, graciosos y picaros". Ideologies and Literature 14 (1977), 3-32.

1 "La formación de la novela latinoamericana", $S N o, 1974$, nủm. 3, p. 5. Para ia palabra extravasante del título, véase infra, p. 212, cita de Maples Arce.

2 A. RAMA, art, cit., p. 5. 
a la insuficientemente ponderada cuestión de su modernización y la ubicación de este proceso en la línea metafórica "recta e irreversible" propuesta por Octavio Paz como medida del flujo temporal de la modernidad ${ }^{3}$.

En Hispanoamérica la modernización socioeconómica y la aparición de la llamada literatura modernista $(\mathbf{1 8 7 0 - 1 8 7 5})^{4}$ son procesos concomitantes cuyos límites y características urge describir y puntualizar no en términos de las disyuntivas sucesivas tradicionales, sino como elementos integrantes de un amplio período de concatenadas discontinuidades, rupturas y metamorfosis.

Vista la modernidad literaria de esta forma, en la ya aludida línea "recta e irreversible" de su progreso constante, la obra experimental de Arqueles Vela se insertaría en la "etapa vanguardista", etapa cuyas innovaciones en verso han sido valoradas más que las de la prosa. La novela vanguardista ha quedado injustamente arrinconada pese a la escritura notablemente renovadora de Pablo Palacio, Macedonio Fernández, Felisberto Hernández, Vicente Huidobro, Oliverio Girondo, Arqueles Vela y otros cuyas novelas anticipan la producción contemporánea a tal punto que se podría modificar la observación de Saúl Yurkiévich, agregando las palabras en cursivas: "La nueva narrativa [la contemporánea] no aporta innovación formal que no haya sido antes practicada por nuestra poesía y la novela de vanguardia".

El estudio de esta prosa a partir de los orígenes del modernismo revela que la narrativa contribuyó al proceso innovador de las letras modernas, hasta ahora asignado exclusivamente al verso, y que en ella los recursos y las técnicas experimentales se dieron en constante producción metamórfica desde el primer brote del arte modernista hasta la narrativa de nuestros días pasando por el período de la vanguardia. De ahí la pertinencia y certeza de las equiparaciones del arte vanguardista con el de hoy establecidas por Luis Mario Schneider, las cuales nos interesa traer a colación y subrayar en esta reconsideración del arte novelístico de Vela como cultivador de una novela renovada y moderna:

Desde hace cerca de diez años -observa Schneider- el mundo contemporáneo vive un ritmo que, de alguna manera, recuerda, en la creación estética, los veinticinco primeros años de este mismo siglo... Es muy común abrir una revista literaria, asistir a una exposición o escuchar un concierto de música sinfónica o popular y advertir de inmediato la similitud que tienen con las creaciones de los movimientos de vanguardia tradicionales. El concretismo alemán y brasileiro, el neosurrealismo europeo y americano, el nadaísmo colombiano, la poesía beatnik, los artes pop y op, los conceptos in y out, las experiencias del grupo Tel Quel...¿qué son sino sensibilidades afines, modos de expresiones en concordancia con las reali-

S El signo y el garabato, México, 1975, p. 12.

* Algunos críticos consideran que en Europa aparece la primera generación de verdaderos escritores modernos, productos de la Ilustración y del Romanticismo alre. dedor de 1880; véase Malcolm Bradbury y James McFarlane, "The name and nature of modernism" en Modernism, Middlesex, 1976, p. 31.

5 La confabulación con la palabra, Taurus, Madrid, 1978, p. 155. 
dades del futurismo, del dadaísmo, del surrealismo, del cubismo, del expre. sionismo, etc. ${ }^{6}$

Dentro de este panorama de transformaciones estéticas la narrativa de Vela escrita en los años veinte 7 viene a ocupar un lugar relevante, pues en ella se descubre una insospechada modernidad cuyas características la crítica hispánica reciente va descubriendo y relacionando con la irracionalidad y el sentido apocalíptico de nuestro mundo contemporáneo.

En consonancia con este nuevo esquema de la evolución de la novela, según el cual vamos revalorando con atraso la actualidad de las creaciones narrativas de los veinte y treinta, es de una ironía significativa -congruente, hubiera sentenciado Vela- que una de las novelas del estridentista, El intransferible (novela "póstuma" escrita entre 1925 y 1927) quedará olvidada hasta 1977 (pub. por Ed. Gama, México). Leída hoy, a la luz de la literatura actual resulta tan moderna que a juicio de Ida Vitale "si no tuviéramos en cuenta la fecha de la escritura de la obra, nos sentiríamos tentados a adjudicar [muchas escapadas de la tradición] a creaciones recientes"8. Vela, por su parte, la consideró un libro "póstumo" porque en su concepto "el hombre muere más de una vez en el decurso de la existencia" (p. 9) -concepto sombrío de la (no) existencia en conformidad con la literatura moderna.

De pareja modernidad es la forma en que el autor de El intransferible se distancia o se separa de la realidad empírica, observando ésta a través de una lupa autorreflexiva y crítica -la de la InNegAuseneia cuyos prismas devuelven los fragmentados perfiles de una serie de negaciones y ausencias representadas con espíritu lúdico y beligerante.

Además de las abundantes negaciones, las ensoñadas ausencias, los lapsos, los desplazamientos y las estructuradas metamorfosis, en esta obra la muerte, la destrucción y la vuelta se interrelacionan y adquieren la trascendencia de "equivalencias"9 cósmicas de un concepto histórico, crítico y cíclico, expresado de modo sistémico/asistemático. Estas interrelaciones de orden destructivo/constructivo son fundamentales en El intrans. ferible, a tal grado que constituyen su eje ideológico y estructural.

Para Vela, cancelar, destruir o negar son maneras de crear desde la orilla de la modernidad. De ahí la lógica de suspender la novela (en lugar de concluirla) con una alusión a la autodestrucción, dejando el narrador constancia de su amistad con Pablo González Casanova en los años veinte (p. 157). Y, por la misma razón es del todo consecuente que el personaje central de la obra, Androsio, "estremecido" y goteando “algunos restos de mujeres" (p. 155), experimente "una sensación de sep. 33.

6 El estridentismo; una literatura de la estrategia, Bellas Artes, México, 1970,

7 Las novelas de Vela de este período son: La señorita Elcétera, Ediciones El Universal Ilustrado, México, 1922. El café de nadie; un crimen provisional, Ediciones de la revista Horizonte, Jalapa, 1926. El intransferible [1925-1927]. Las citas en el texto son de estas ediciones.

8 Reseña de El intransferible, Vuelta, 1977, mum. 12, p. 45.

9 Para una aclaración del concepto de las "equiralencias", véase infra, p. 211, cita de Maples Arce. 
guir asi, de recomenzar así..." (la negación y el ciclismo ya aludidos) en el apartado final de la obra titulado simbólicamente "la trasnoche".

Androsio es el hombre primordial, el ser arquetípico de "inmovilidad androginosa" quien, al buscar la palabra - ¿el verbum primitivo?-, vuelve "al principio; al lugar de partida de los ecos... [donde] tan sólo un grito algaraboso resonaba..." (p. 156).

Los ecos, la palabra confusa, la búsqueda de los origenes y las alusiones a la mitología indígena de México sugieren el retorno a lo primigenio, el "re-volver" revolucionario que explicara Octavio $\mathrm{Paz}$ al deslindar la búsqueda del hombre moderno de su historia ${ }^{10}$, vía, y como secuela de, la negación de su mundo contemporáneo, actualizando el pasado -el maya y azteca en el caso de $E l$ intransferible-, todo en forma fragmentaria, angular y desconectada como lo querían los estridentistas en su afán de representación cubista. Por lo tanto, Androsio, el antagonista (p. 7) de la experiencia humana y universal (instrumento de la colectividad rememoriada), también es el agonista (el ser alienado frente a la colectividad) que presencia el fraccionado, absurdo caos universal: "Por un momento se sintió abandonado; próximo a naufragar en el diluvio invasor, poco a poco, de su aislamiento desarraigado, al unísono, de las perspectivas alambrados a los 4 puntos cardinales; mientras subían en un elevador exposicional, los paisajes subrayados en los Baedekers; transportándole sistemáticamente a una solemne inauguración” (p. 116).

Por medio de estos "transportes" el novelista hace deambular a su antagonista por una realidad corporal/incorporal en la cual Androsio experimenta la agonía de un universo descosido, y desde cuyos bordes infinitos es espectador de la acelerada máquina del universo futurista y de un mundo tecnológico, deshumanizado y materialista. Pero, también es testigo del pasado primitivo: baja a las entrañas de los orígenes humanos donde escucha las primicias lingüísticas incoherentes como "Elenmartirigoyen, Matilgojesanda, Espesurquiza, Delisarcos, Carmelinda" (p. 60) .

En este hilvanar de experiencias en el que el ser/no ser se mueve entre los polos más distantes de la existencia, el tiempo se transforma, se estanca, y se niega: es un tiempo "sin punto fijo" (p. 119), pero "pasaba cronológicamente". El sol "giraba... .sin llegar jamás al poniente" ( $p$. 119). Y cuando "Androsio volvió a examinar su reloj. Ninguna hora" (p. 121). Como testigo y vidente moderno, la óptica de Androsio es prismática y a la vez comprensiva: abarca el tiempo desarraigado, estéril y fragmentario; la emoción social - "cada 17 segundos moría alguien de frío en las grandes avenidas" (p. 124) ; y los planos y receptáculos de un continuum temporal y espacial cuyo momento y punto de descanso son sugeridos al margen de varios principios y fines enunciados en forma de canto mágico: el transmutador, el generatriz, el conmutador, el aislador, el acumulador- y su polo opuesto: el reposo universal (p. 57). El reposo denota el fin de un ciclo, el terminus histórico, en contraste con los demás principios representativos de la dinámica concepción de la vida moderna reflejada en la estructura proteica y poliforma de la novela.

10 Véase Cuadrivio, México, 1965, pp. 21-25. 
Además de las antítesis y las contradicciones abundan las paradojas características de la modernidad, tanto como la burla y la parodia indicadoras del distanciamiento, la crítica y, a la vez, la ineludible y a menudo involuntaria identificación del hombre moderno con su existencia histórica, contemporánea o pretérita. Del pasado presenciamos la corte de una tribu legendaria a la cual es llamado Androsio por delincuente. Con detalle hiperbólico, remedo y burla de la exuberancia primitiva y de la obsesión estadística moderna, el narrador cuenta que el jefe apareció para sentenciar a Androsio con su séquito de " 500 mujeres legítimas, a la derecha; 500 mujeres ilegítimas, a la izquierda; . .2,000 mujeres suplentes... [con] las concubinas fijas y pasajeras, las subfijas y reprobadas", inclusive las más altas de "una dignidad incorporal" (pp. 42-43). En otro pasaje, al describir a Alicia, anota en forma tabular: "Tobillos$71 / 2$ pulgadas; Pantorrillas- 133/4; Muslos- 18; Caderas- 331/2; etc.", y, a continuación se funden con tono festivo la picardía sensual, la hipótesis científica y el apotegma filosófico: "eres tan coqueta que debes cruzar las piernas al subirte en el W. C. ... Primero... siento tus caricias... Segundo... las presiento... Tercero... se quedan flotando entre ambas sensaciones. . luego, ya no sé nada..." (o. 99) . O, aproximando su lente burlón a la realidad social, el novelista nos confronta con una camarada revolucionaria que envía a su jefe de sectores un parte cuyo comienzo paródico está exento de los tabúes lingüísticos observados en la época sobre todo por las mujeres: "Ya giro mis chingonas órdenes, a fin de que... ese jijo del siete negro -impar en aquellas regiones- no siga jodiendo, a priori". X, concluye, "... si las mordeduras vuelven a registrarse en lo relativo al reparto de la igualdad, iré a efectuar el intronizamiento (sic) de la ley, a fortiori, personalmente, etc., etc., etc..." (pp. 53-54).

El anverso de la parodia es la reintegración del fragmentario mundo del antagonista, armonía que se transparenta en la estructura de la obra cuyos capítulos constituyen un día metafórico precedido de una "prenunciación" y una "trasnoche" al final: "La madrugada", " $1 / 4$ Ante Meridiem", "Mediodía", "La noche", "Five o'clock mitin". Se evidencia también en el espacio novelístico, en el tránsito témporo-espacial del viaje simbólico de Androsio. Sus aventuras se inician en la esfera ínfima de las tinieblas, con una especie de rito de iniciación en el sótano de María del Carmen. Y terminan con su silencio, su posible muerte, en una esfera empírea con la cabeza echada por el tragaluz de una buhardilla donde es asediado por unas harpías de "alas manteladas". Siente que su visita crea una sensación de acabar: "no las presencié -observasino las postesencié" (p. 154). Postesenciar implica la conclusión de una etapa al alejarse Androsio de sus nexos concretos: "Tan solo yo persistía"; "Tan sólo yo, solo, quedaba". Y, al acelerarse este proceso de alejamiento, se produce la vuelta a un principio: "su cuerpo oscilante, se estabilizaba en la inmovilidad circunstancial de las cosas" (p. 156).

La reintegración al cosmos constituye una afirmación ontológica: en lugar del fragmentarismo, la unidad; en lugar del aislamiento, la consustanciación; frente a la InNegAusencia, la multipresencia. Los conceptos del uno (el ser) y el todo (el universo), y del uno en el todo están 
implícitos en la noción de vueltas, metamorfosis y transubstanciaciones. Y, están confirmados por el juego numérico, sobre todo el de los grupos o las combinaciones de 3 y de 7 , indicadores del corpus total y del flujo, por un lado, y por otro, de la unidad: "Se volvió, rápido, convencido de no obtener jamás la hora precisa.-3, 9, 12, 15, 18, 99, 333" (p. 44); "Has vencido a 7 hombres" (p. 56). Se podría considerar la insistencia sobre los números un reflejo de la predilección azarosa del escritor por el espíritu científico y las ciencias exactas de la sociedad tecnológica. Pero, también se plantea la posibilidad de un trasluz cultural más remoto (los orígenes) con base filosófica, o sea, la numerologia, según la cual, en su formulación pitagórica, el 7 sería el símbolo de las vicisitudes de la vida (el todo), y el 3, la armonía perfecta (el ya aludido reposo universal) .

Pese a estas formulaciones numerológicas no fue Vela el portavoz ideológico de los estridentistas, sino List Arzubide y Maples Arce; éste, en una hoja volante (Actual, No 1), puntualizó las relaciones entre los objetos y su representación artística. Y, en el mismo número aludió a la plasmación esférica de la emoción humana11 y de los nexos entre emoción y arte: "La verdad estética, es tan sólo un estado de emoción incoercible desarrollado en un plano extravasal de equivalencia integralista [donde] las cosas no tienen valor intrínseco posible, y su equivalencia poética, florece en sus relaciones y coordinaciones" (ibid., p. 37)

Según Maples, lo anímico se traslada, se fragmenta y se relativiza develando un perspectivismo tanto estético como filosófico en que el fenómeno en sí es parcial, delimitado por el espacio y el tiempo, y definido sólo por su relación con la alteridad y la carencia. En El intransferible hay "vasos comunicantes" entre la percepción subjetiva de una sensación o de un pensamiento y su proyección objetiva hacia formas armoniosamente geométricas o arquitectónicas, y entre su relación diacrónica y arquetípica, entre su metamorfosis y éstasis, entre su divisibilidad polar y su coordinación unitaria y andrógina.

Lo sensorial vago, afelpado y diluido de $E l$ café de nadie y La señorita Etcétera se concentra en la óptica y la audición en $E l$ intransferible en cuyas páginas a menudo la sensación se arrebuja en espacios volumétricos, receptáculos ahuecados o encrucijadas de lo interno exteriorizado: "Los viajeros iban y venían de una esquina a otra de la impaciencia" (p. 44). A veces a una consciente y ya tradicional reiteración sonora de fonemas y sintagmas - "haciendo titilar la tarlatana transparente del amanecer" (p. 21) - se agregan juegos verbales experimentales como los caligramas, los neologismos basados en injertos silábicos - "sexiprocidad" y "aviónfrago"-; y la adición de letras superfluas como la "h" en " ${ }^{H} \mathrm{HA}_{\text {- }}$ LLí viENE EL otro!..." (p. 60), o la eliminación de otras. En éstos y otros recursos expresivos Vela reduce lo legendario de la supuesta "lengua arcaica" a la parodia; ésta puede ser de tipo etimológico como en el caso de la yuxtaposición de los nombres de las tres mujeres, las llamadas "chingamusas", chINAM-GAG-HADA, término compuesto que representa la trinidad femenina y cuyas partes integrantes significan la aven-

11 Citado por SCHNerder, El estridentismo, p. 39. 
tura creadora, el fuego destructor y la diosa fantástica. Mediante la síntesis semántica, la eliminación o absorción de letras, todo se reduce a la chingada (p. 55) ${ }^{12}$.

El sexo, en especial la relación mujer/hombre es central, omnipresente y contradictoria en este relato, sugiriendo una polaridad imantada hacia un reposo milenario, andrógino. A menudo, la relación heterosexual es más mecánica que erótica tanto para el hombre como para la mujer. Frente a las tres princesas, "Androsio estuvo en cada una de ellas una sola vez y después prosiguió su camino, sin preguntar sus nombres" (p. 43) . O cuando las revolucionarias "pasaban y pasaban y salian sin éxito, porque Androsio permaneció inepto. Intacteable" (p. 57). En otra ocasión la mujer del café en Berlín bate el récord de 15 minutos de gimnasia sexual con él. En efecto, Androsio y las mujeres parecen ser poco más que "turistas del amor" (p. 30), es decir del sexo, como los calificaba Mabelina en El café de nadie.

La bipolaridad masculina/femenina deviene trinidad sexual explicitada en tono de relajo en el episodio del mitin feminista: ". . . hay tres sexos: masculino, femenino y yo..." (p. 104). A pesar de la nota burlona, esta afirmación constituye una de las coordenadas que aparece tanto en El intransferible como en $E l$ café de nadie: la fragmentación relativa del personaje y su síntesis totalizadora que antitéticamente niega el fenómeno espacio-temporal de sus componentes. En El café de nadie un hombre nos muestra su mutabilidad cuando afirma que "Soy un individuo que se está renovando siempre" (p. 28), y el narrador le atribuye a una mujer, Mabelina, una esencia tanto caleidoscópica como ausente, porque "después de ser todas las mujeres ya no era nadie" (p. 38). En El intransferible Androsio "hubo de vivir siempre, representando algún otro" (p. 89) en un deambular por el camino de la vida sombría y humeda, es decir, misteriosa, mágica, creadora. No es actor sino espectador de la otredad, de las transformaciones de la mujer, de la femeneidad vuelta a sus raíces arquetípicamente terrenales.

Vuelta selva, barro, criatura amorfa, la mujer se rebela negándose a revelar su sexualidad; se convierte en materia prima, neutra, eterna. La mujer de barro dejó a Androsio impotente y mudo, "en una incompetencia física absoluta" (p. 84), mientras que la mujer zoomorfa se extendió como una $\infty$ "haciéndose la infinita" (p. 140), hasta que Androsio se agazapó ante ella y "ambos permanecieron en una inmovilidad androginosa" (p. 140), el sexo de ella "como un tabernáculo, en donde nadie podría oficiar nunca..." (p. 142). Poco después de ese encuentro, vestido de pijama, fetiche oloroso a mujer, Androsio andará por las calles y ante un grupo de prostitutas políglotas proclamará iróni-

12 Según I. Vitale, reseña citada, este juego "es de empleo bastante usual hoy en un Cabrera Infante, entre otros ejemplos posibles, y resulta de una sorprendente modernidad cincuenta años atrás" (p. 45). Vela, en un trabajo publicado poco antes de su muerte, observó que "la necesidad de expresión promueve siempre la crea. ción de neologismos que comienzan por onomatopeyas sin sentido claro y terminan en fonemas precisos. "JJames Joyce: babelbalbuceismo" en Diorama de la Cultura de Excelsior, oct. 30 de 1977, p. 3. 
camente la naturaleza neutra, andrógina de la mujer: "Oh, Mädchen... Mädchen... Mädchen... dein Name ist Sächlich... (p. 88).

Lo femenino se le presenta a Androsio en El intransferible y al narrador de otras obras de Vela como La señorita Etcétera en forma antitética, tangible pero, en el fondo, inasible, mortal aunque arquetípicamente eterna, "compleja de"simplicidad, clara de imprecisa, inviolable de tanta violabilidad" (p. 93). Aún cuando la mujer le despierta al hombre hacia un sueño como en La señorita Etcétera ella llega a ser objeto sexual, "perversátil", como una silla momentáneamente desocupada, o un "apartamento cualquiera, como esos de los hoteles, con servicio 'cold and hot' y calefacción sentimental para las noches de invierno..." (p. 89). El hombre por su parte siente la fatal necesidad sexual de la mujer, porque como dicen las feministas del mitin sindicalista, "...qué es el hombre, sino la reacción de la mujer" (p. 104), y ésta le incuba, le inicia y le proporciona tanto la muerte lenta del sexo como la definitiva de la vida.

En la escena final de la novela, Androsio espera la llegada a su buhardilla de una mujer que parece la sombra de la Venus de Granach del cuadro en la pared o la proyección de "un sensualismo intelectual" como lo había dicho Vela en $E l$ café de nadie (p. 31). Abandonado por esa sombra platónica del amor, mientras medita solo en su habitación sobre las sensaciones que había experimentado él o posiblemente su otro, lo visitan criaturas aladas fantásticas que le imploran pronunciar una palabra cualquiera. Androsio no pudo hacerlo antes. Tampoco ahora. Se siente regresar al principio, al lugar del eco, tal vez, a la nada interuterina o a la muerte. Pero después de verlas partir hacia el cielo, se da cuenta de la necesidad complementaria que existe entre hombre y mujer, de su separación y de su unión cíclica fatal, de la síntesis andrógina en busca del reposo armónico de sus contrapartes, o como lo había expresado Maples Arce en cuanto a la verdad estética, de "la emoción incoercible desarrollada en un plano extravasal de equivalencia integralista":

...por lo tanto más bien nos acercamos... alguien hacia mí, en forma de ellas y yo hacia ella, en forma de él... luego, al encontrarnos sin reconocernos ni desconocernos, fuimos los mismos de aquellos y separados en seguida, un instante, para juntarnos después otros muchos ciclos, nos contaminábamos la sensación de actuar ambos, no siendo sino la divisibilidad de uno y otro, o de cada uno, cada cual complementario (p. 155).

Estas son las equivalencias interrelacionadas de modo dinámico, multiforme y eterno, denotadoras de un ciclismo InNegAusente y extraVasal en esta obra perdida de Vela a cuya lectura nos acercamos después de un lapso de cincuenta años. En ella descubrimos con asombro unas características tan modernas como las experimentales, renovadoras creaciones de la novela contemporánea. Y esta desconcertante verdad obliga a meditar otra vez sobre las ya citadas correspondencias temporales y artísticas sentadas por Luis Mario Schneider: "el mundo contemporáneo vive un ritmo que... recuerda en la creación estética, los veinticinco primeros 
años de este mismo siglo". ¿Se trata de una anomalia aislada en el caso de Vela? Estamos persuadidos que no. La relectura y la revaloración de las novelas de la "vanguardia" y de algunas narraciones sui generis del periodo (e. g.: Espantapájaros de Oliverio Girondo, las novelas ejemplares de Huidobro o las tenebrosas novelas cortas de Pablo Palacio) revelarán un fondo de obras igualmente modernas, tan desconcertantes $y$ actuales como El intransferible.

Evelyn Picon Garfield

Wayne State University.

Ivan A. Schulman 